\title{
Identification of nanometre-sized ultra-high molecular weight polyethylene wear particles in samples retrieved in vivo
}

\section{Richards, \\ C. Brown, \\ M. H. Stone, \\ J. Fisher, \\ E. Ingham, \\ J. L. Tipper}

From The University

of Leeds, Leeds,

England
L. Richards, BSc(Hons),

Postgraduate student

In C. Brown, BSc(Hons), PhD,

Postdoctoral Research Fellow

v. J. Fisher, PhD, DEng,

Professor of Mechanical

Engineering

E. Ingham, PhD, Professor of

Medical Immunology

J. L. Tipper, PhD, EPSRC

Advanced Research Fellow

Institute of Medical and

Biological Engineering (iMBE),

Faculty of Biological Sciences

University of Leeds, Leeds LS2

9JT, UK.

M. H. Stone, MBChB, FRCS(Edin), Consultant

Orthopaedic Surgeon

Department of Orthopaedic

Surgery

Chapel Allerton Hospital,

Chapeltown Road, Leeds LS7

4SA, UK.

Correspondence should be sent to Dr J. L. Tipper; e-mail:

j.l.tipper@leeds.ac.uk

(C)2008 British Editorial Society of Bone and Joint Surgery doi:10.1302/0301-620X.90B8. $20737 \$ 2.00$

$J$ Bone Joint Surg $[\mathrm{Br}]$

2008;90-B:1106-13.

Received 14 January 2008;

Accepted 18 March 2008

Nanometre-sized particles of ultra-high molecular weight polyethylene have been identified in the lubricants retrieved from hip simulators. Tissue samples were taken from seven failed Charnley total hip replacements, digested using strong alkali and analysed using highresolution field emission gun-scanning electron microscopy to determine whether nanometresized particles of polyethylene debris were generated in vivo. A randomised method of analysis was used to quantify and characterise all the polyethylene particles isolated.

We isolated nanometre-sized particles from the retrieved tissue samples. The smallest identified was $30 \mathrm{~nm}$ and the majority were in the $0.1 \mu \mathrm{m}$ to $0.99 \mu \mathrm{m}$ size range. Particles in the $1.0 \mu \mathrm{m}$ to $9.99 \mu \mathrm{m}$ size range represented the highest proportion of the wear volume of the tissue samples, with $35 \%$ to $98 \%$ of the total wear volume comprised of particles of this size. The number of nanometre-sized particles isolated from the tissues accounted for only a small proportion of the total wear volume. Further work is required to assess the biological response to nanometre-sized polyethylene particles.

As the femoral and acetabular components of a hip replacement articulate, ultra-high molecular weight polyethylene (UHMWPE) particles are released into the peri-prosthetic tissue. ${ }^{1,2}$ They initiate an inflammatory response which, inevitably in the long term, results in aseptic loosening of the implant, with bone at the bone-implant interface being resorbed by osteoclasts. 3,4

Previous studies have shown that particles isolated from the lubricating fluid from hip and knee simulators and tissues from failed total joint replacements, have a wide range of morphologies and sizes. Tipper et $\mathrm{al}^{2}$ identified particles ranging from $0.1 \mu \mathrm{m}$ to $1000 \mu \mathrm{m}$ in tissues surrounding Charnley hip prostheses. Previously, UHMWPE debris has been characterised using oil red $\mathrm{O}$ staining ${ }^{5}$ and polarised light microscopy, which gives a classic birefringent glow surrounding the polyethylene. ${ }^{6}$ However, these two techniques fail to separate and accurately size agglomerated particles. Preferred methods now involve digesting and isolating particles that can then be visualised using scanning electron microscopy (SEM). ${ }^{7-15}$ Conventional SEM has a resolution of approximately $0.1 \mu \mathrm{m}$, and thus until recently particles were only characterised in the size range $0.1 \mu \mathrm{m}$ to $10 \mu \mathrm{m}$.

Galvin et $\mathrm{al}^{16}$ and Tipper et $\mathrm{ll}^{17}$ used highresolution field emission gun-scanning electron microscopy (FEG-SEM) to analyse wear particles isolated from the lubricants used in hip and knee simulators, and identified UHMWPE particles down to $10 \mathrm{~nm}$ in size. Scott et al ${ }^{10,18}$ also recently identified UHMWPE particles down to $80 \mathrm{~nm}$ in size in the lubricant retrieved from hip simulators.

It is not known, however, whether nanometre-sized particles are generated in vivo and/or retained in peri-prosthetic tissue, and it was the aim of this study to determine whether particles $<0.1 \mu \mathrm{m}$ in size exist in tissues surrounding failed total hip prostheses.

Particle size is believed to be an important factor in determining the biological response to wear debris and those in the size range of $0.1 \mu \mathrm{m}$ to $1.0 \mu \mathrm{m}$ have been shown to be most biologically active in terms of initiating a cellular response in vitro. ${ }^{19-21}$ If nanometre particles are generated in vivo it will be important to determine their biological activity in relation to that of micrometre-sized particles.

\section{Materials and Methods}

Samples of femoral tissues from seven patients were collected at revision operations performed by one surgeon (MHS). The tissues were stored in $10 \%(\mathrm{v} / \mathrm{v})$ neutral buffered formalin at room temperature. All the prostheses were Charnley (DePuy International, Leeds, United Kingdom) total hip replacements 
(THR), with a monoblock stainless steel stem $(22.2 \mathrm{~mm}$ head) articulating with a UHMWPE acetabular component produced from GUR 1120 resin (Ticona, Oberhausen, Germany), which had been gamma irradiated in air. The mean time from implantation to revision was 14.1 years $(9.25$ to 19). All revisions were due to aseptic loosening. The initial indication for THR was osteoarthritis in all cases.

Samples of the lubricant were investigated from seven hip simulator stations for direct comparison with the tissue samples. The tests were carried out in a Prosim hip simulator (Simulator Solutions, Manchester, United Kingdom). The UHMWPE component, with a femoral head $28 \mathrm{~mm}$ in diameter, was produced from GUR1050 resin sterilised by 25000 Grays gamma radiation in air. All tests were carried out in $25 \%(\mathrm{v} / \mathrm{v})$ bovine serum (mycoplasma and virus screened, 16030-04, Gibco Life Technologies Ltd, Paisley, United Kingdom), which was diluted with $0.1 \%(\mathrm{w} / \mathrm{v})$ sodium azide to retard bacterial growth. The acetabular components were positioned superiorly and inclined at $35^{\circ}$ to the horizontal in an anatomical configuration. The acetabular insert underwent $+10^{\circ}$ rotation. Two independent controlled movements were applied to the femoral head of flexion $\left(+30^{\circ}\right)$ and extension $\left(-15^{\circ}\right)$. Full details of the loads and movements of the simulator have been described by Tipper et al. ${ }^{17}$ The simulator was run to five million cycles. The lubricants were collected between two and five million cycles.

Isolation of polyethylene wear debris from the simulator lubricant. Wear debris was isolated using the method of Tipper et al, ${ }^{2}$ which was optimised to ensure complete digestion and removal of biological contaminants. A total volume of $60 \mathrm{ml}$ lubricant per sample was digested using $12 \mathrm{M}$ potassium hydroxide (Fisher Scientific, Loughborough, United Kingdom) in aliquots of $10 \mathrm{ml}$. Lubricants were incubated in a water bath at $60^{\circ} \mathrm{C}$ over three to four days until fully digested. A volume of $10 \mathrm{ml}$ chloroform:methanol 2:1 mix (VWR International, Poole, United Kingdom) was added to each sample and incubated at room temperature for 24 hours. Samples were centrifuged at $500 \mathrm{~g}$ for ten minutes at room temperature, and the supernatant was decanted into a clean universal container. The chloroform:methanol/centrifuge steps were repeated three to four times until the supernatant was visibly clear. Samples were then pooled and an equal volume of 96\% (v/) absolute ethanol (VWR International Ltd) was added to precipitate proteins. Ultra-pure water (Fresenius Kabi, Warrington, United Kingdom) was then added until the solution turned transparent, which required approximately $100 \mathrm{ml}$. The samples were incubated overnight at $4^{\circ} \mathrm{C}$ with stirring. Samples were centrifuged at $20200 \mathrm{~g}$ for two hours at $4^{\circ} \mathrm{C}$. The supernatant was decanted and an equal volume of Ultra-pure water was added in preparation for filtration.

Isolation of polyethylene wear debris from tissue samples. Approximately $1 \mathrm{~g}$ of femoral tissue was digested from each patient, and this comprised a random selection of tissue from the complete peri-prosthetic sample. Tissue samples were finely chopped and digested in $10 \mathrm{ml}$ of $12 \mathrm{M}$ potassium hydroxide (Fisher Scientific) with incubation at $60^{\circ} \mathrm{C}$ over five to eight days until fully digested. A volume of $10 \mathrm{ml} \mathrm{2:1} \mathrm{chloroform:methanol} \mathrm{mix} \mathrm{(VWR} \mathrm{International)}$ was added to each sample and incubated at room temperature for 24 hours. Samples were centrifuged at $500 \mathrm{~g}$ for ten minutes at room temperature, and the supernatant was decanted into a clean universal container. The chloroform:methanol/centrifuge steps were repeated three to four times until the supernatant was visibly clear. An equal volume of $96 \%$ (v/v) absolute ethanol (VWR International) was added to precipitate proteins. Approximately $100 \mathrm{ml}$ Ultra-pure water (Fresenius Kabi) was added until the solution turned transparent. The sample was incubated overnight at $4^{\circ} \mathrm{C}$ with stirring. Samples were centrifuged at $20200 \mathrm{~g}$ for two hours at $4^{\circ} \mathrm{C}$. The supernatant was decanted and an equal volume of Ultra-pure water was added in preparation for filtration.

Preparation of filters. Before filtration of tissue samples a series of $10 \mu \mathrm{m}, 1 \mu \mathrm{m}$ and $0.015 \mu \mathrm{m}$ polycarbonate membrane filters (Whatman International Ltd, Maidstone, United Kingdom) were washed using $20 \mathrm{ml} \mathrm{70 \%} \mathrm{(v/v)}$ ethanol (VWR International). The filters were dried for a minimum of four hours under infra-red heat lamps in a moisture-controlled environment. The filters were then weighed five times using a Mettler microbalance (MSE Scientific Instruments, Crawley, United Kingdom) with a stated accuracy to $1 \mu \mathrm{g}$. From this point, tissue and simulator lubricant digests were processed in the same way.

Filtration of digested samples of both tissue and serum lubricant. The solutions were filtered through a sequence of $10 \mu \mathrm{m}, 1 \mu \mathrm{m}$ and $0.015 \mu \mathrm{m}$ polycarbonate membrane filters (Whatman). The filters were then dried under an infrared lamp for two to three hours. Filters used for filtering the tissue samples were dried for a further four hours and reweighed as described above before FEG-SEM analysis. Filtration and drying took place in a class I laminar flow cabinet. The filters were mounted on aluminium stubs with double-sided carbon pads and sputter-coated with $5.0 \mathrm{~nm}$ platinum/palladium (Agar Scientific Ltd, Stansted, United Kingdom). Samples were analysed by high-resolution LEO 1530 FEG-SEM (LEO Electron Microscopy Ltd, Cambridge, United Kingdom).

Quantification of UHMWPE wear debris. An objective method of microscopy was developed in order to eliminate bias in sizing. A total of five random fields of view were taken over three or four ranges of magnification per filter to ensure randomisation of methods of microscopy, as detailed in Table I.

Images were analysed using Image Pro Plus image analysis software 4.5.1 (Media Cybernetics, Silver Spring, Maryland), and the maximum diameter of the particles and their area was measured. A minimum of 200 particles were counted for each sample, but in most cases more than 500 were measured. The total area of the image being analysed 
Table I. Magnification ranges for each filter

\begin{tabular}{llll}
\hline Filter membrane pore size $(\boldsymbol{\mu m})$ & Magnification range (kilo) & Fields of view & Total number of fields of view \\
\hline 10 & 0 to 4 & 5 & 15 \\
& 4 to 10 & 5 & \\
& 10 to 15 & 5 & 20 \\
1 & 0 to 10 & 5 & 5 \\
10 to 20 & 5 & 20 \\
20 to 30 & 30 to 60 & 5 & \\
0.015 & 0 to 35 & 5 & 5 \\
& 35 to 50 & 5 & \\
& 50 to 65 & 5 to 100 & 5 \\
\hline
\end{tabular}

was deduced using Image Pro Plus software and defined as area A. Data were exported to a Microsoft Excel (Microsoft, Münster, Germany) spreadsheet and sorted by ascending length of the particles. The particles were grouped according to length into one of the following size ranges: $<0.1 \mu \mathrm{m}, 0.1 \mu \mathrm{m}$ to $0.99 \mu \mathrm{m}, 1.0 \mu \mathrm{m}$ to $9.99 \mu \mathrm{m}, \geq 10 \mu \mathrm{m}$. The number of particles in each size range was counted $(\mathrm{N})$. The sum of the particle areas, for each size range was computed $(\mathrm{P})$. Values for N/A and $\mathrm{P} / \mathrm{N}$ were calculated, and from that the percentage number of particles and the percentage area of the particles in each size range were evaluated for illustrative purposes.

Energy dispersive $\mathrm{X}$-ray analysis to eliminate non-polyethylene particles. Particles of all morphologies were analysed using energy dispersive X-ray analysis (Oxford Instruments, INCA 350 EDX system, Abingdon, United Kingdom). Polyethylene cannot be positively identified using this method of analysis. A reference trace was taken of the polycarbonate filter membrane, and this was subtracted from the traces of particles that had been isolated from the samples and analysed. Traces which showed similar peaks to the polycarbonate reference trace were considered to be UHMWPE.

Control samples. A total volume of $60 \mathrm{ml}$ fetal bovine serum (Gibco Life Technologies Ltd) was digested following the protocol for the hip simulator lubricants described above and used as a negative control. Control sample digests were repeated throughout the course of the study. The total number of contaminating particles was counted and an estimate of their percentage calculated as follows:

\section{Total number of contaminating particles on control sample filter \\ Total number of particles in a sample of hip simulator lubricant} $\mathrm{x} 100$

Statistical analysis. Samples came from individual patients and were therefore not strictly comparable. However, it was interesting to compare the mean percentage number of particles isolated in each size range from the simulator lubricants to the mean percentage number of particles isolated from the tissue samples. The percentage data were arcsin transformed ${ }^{22}$ and analysed by one-way analysis of variance (ANOVA). The differences between the lubricant sample group and the tissue sample group means were determined by calculating the minimum significant difference $(\mathrm{p}<0.05)$ by the T method. ${ }^{22}$

\section{Results}

Characterisation of UHMWPE particles isolated from periprosthetic tissue samples. Particles that were less than $0.1 \mu \mathrm{m}$ long and therefore in the nanometre size range were identified in all samples of peri-prosthetic tissue. Particles isolated from the tissue samples were varied in size and shape. Long thin particles above $10 \mu \mathrm{m}$ in length were referred to as fibrils, and shorter, narrow particles were described as fibril like. Nanometre-sized debris tended to be regular in shape and rounded, with a granule-type morphology as shown in Figure 1a. Flake-like particles generally appeared flat and varied in size and shape. Much of this fibril- and flake-like debris was difficult to size because the polyethylene was intertwined, as shown in Figure 1b. The image analysis software was not able to distinguish agglomerates. Therefore, all sizing was carried out manually, eliminating the possibility of error and over-estimation of particle size. The longest particle of polyethylene isolated from the tissue samples was $0.52 \mathrm{~mm}$ long and the smallest was $30 \mathrm{~nm}$ (Fig. 1a).

Characterisation of UHMWPE particles isolated from simulator lubricant samples. Particles isolated from the simulator lubricants showed similar morphologies to those obtained from the tissue, with fibrils, flake- and fibril-like agglomerations like those shown in Figure 1b, and granules similar to the particles shown in Figure 1a. Particles which were less than $0.1 \mu \mathrm{m}$ long, and therefore in the nanometre size range, were identified in all simulator lubricants, and were more numerous than those isolated from tissues. As with the particles isolated from the tissues, fibril- and flake-like 


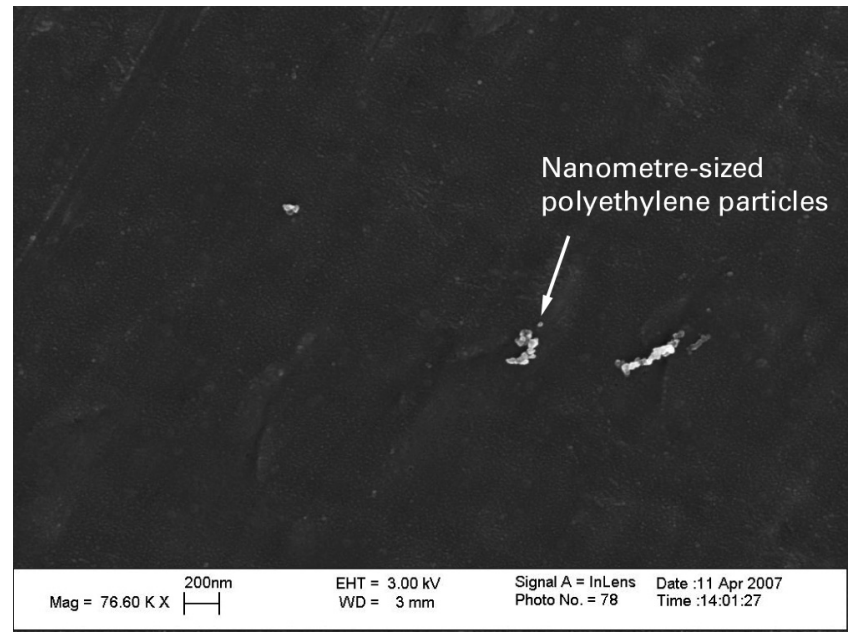

Fig. 1a

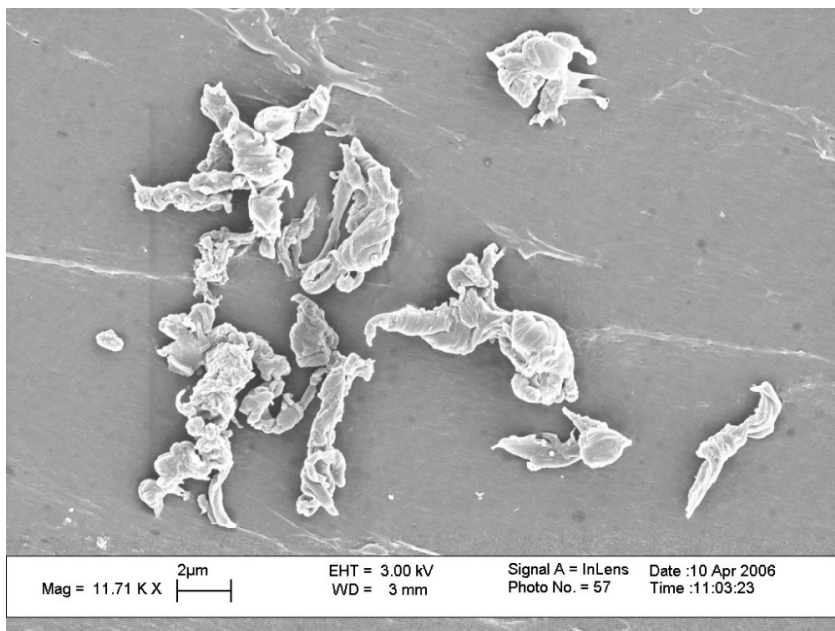

Fig. 1b

High-resolution field emission gun-scanning electron microscope images of polyethylene debris isolated from the peri-prosthetic tissue samples showing a) nanometre-sized granular type particle (30 $\mu \mathrm{m}$ in size), isolated from tissue sample 6 on a $0.015 \mu \mathrm{m}$ filter ( $\times 70600$ magnification), and b) fibril-like agglomerates of polyethylene particles isolated from tissue sample 4 , on a $0.015 \mu \mathrm{m}$ filter ( $\times 11710$ magnification).

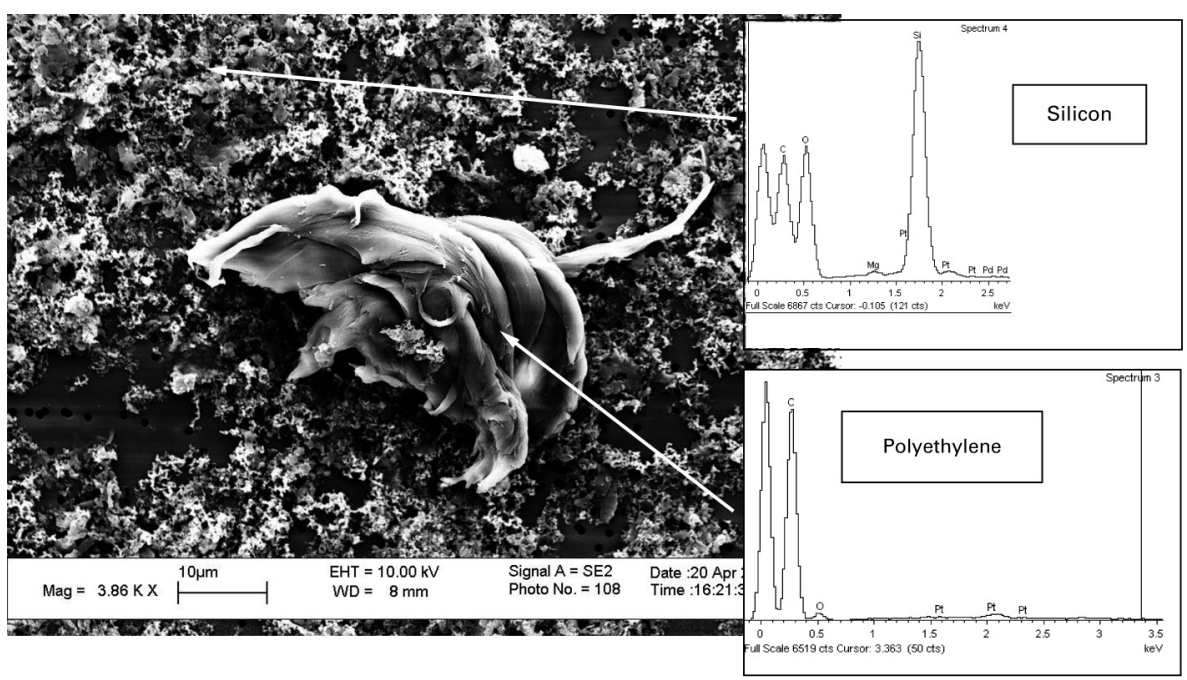

Fig. 2

Energy dispersive X-ray trace (upper right spectrum) showing a vast quantity of silicon debris contaminating a $1 \mu \mathrm{m}$ filter. Above the contamination is a large particle of polyethylene (EDX trace, bottom right).

particles commonly formed aggregates. The smaller, rounded granular debris was abundant, and the majority settled on the $1 \mu \mathrm{m}$ filter. The longest particle of polyethylene isolated from the hip simulator lubricants was $0.47 \mathrm{~mm}$ and the smallest was $21 \mathrm{~nm}$.

EDX analysis. The dominant peaks for the polycarbonate filter were carbon and oxygen, and trace elements were shown for platinum, aluminium, potassium and silicon, all at a very low level. Most traces contained peaks referenced as platinum and palladium, as all samples were coated using these two elements. Where the trace contained elements of carbon, hydrogen and oxygen and appeared similar to that of the polycarbonate filter, trace particles were accepted as polyethylene. Silicon was a particular problem as a contaminant. The extreme contamination experienced during analysis of particles isolated from tissue sample 6 is demonstrated in Figure 2, and the flake-like particle positioned above the silicon contaminant is polyethylene. In this case the digestion was repeated, as accurate size analysis and quantification of the polyethylene particles isolated 


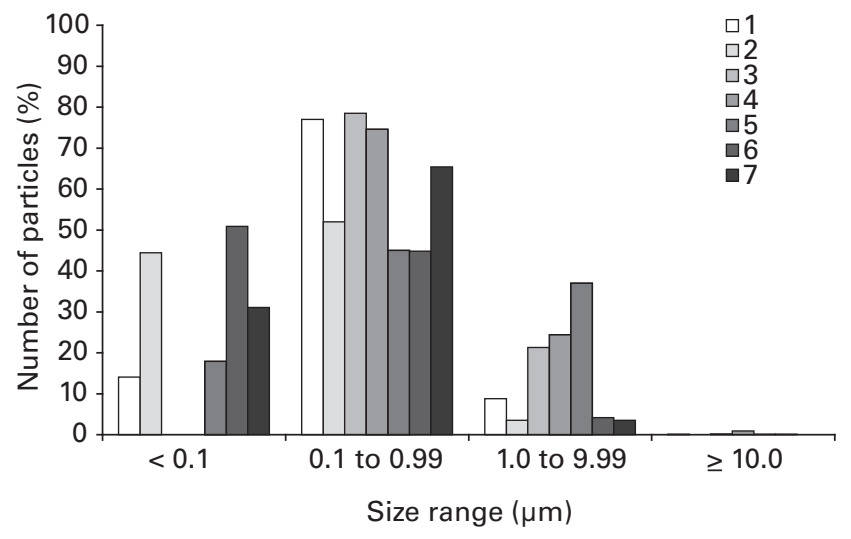

Fig. 3a

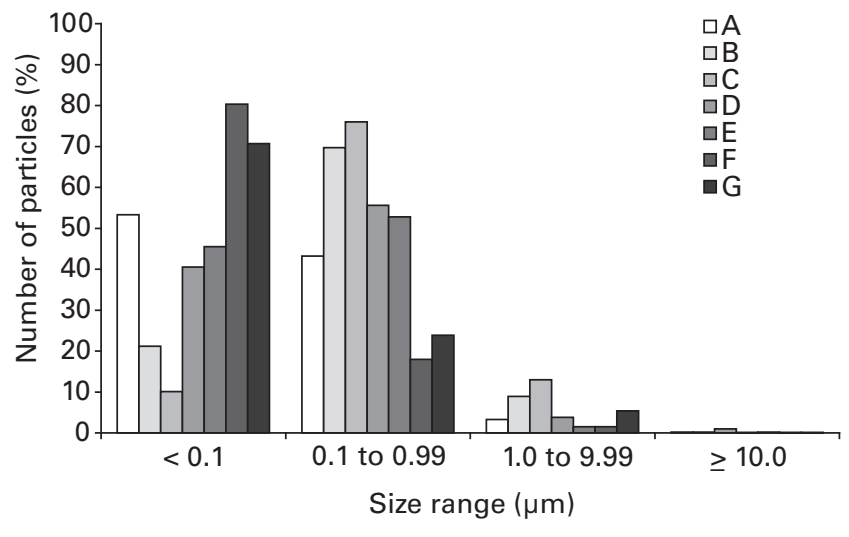

Fig. $3 b$

The size distribution of ultra-high-molecular-weight polyethylene particles isolated from a) the seven samples of tissue compared with b) the seven samples of simulator lubricant.

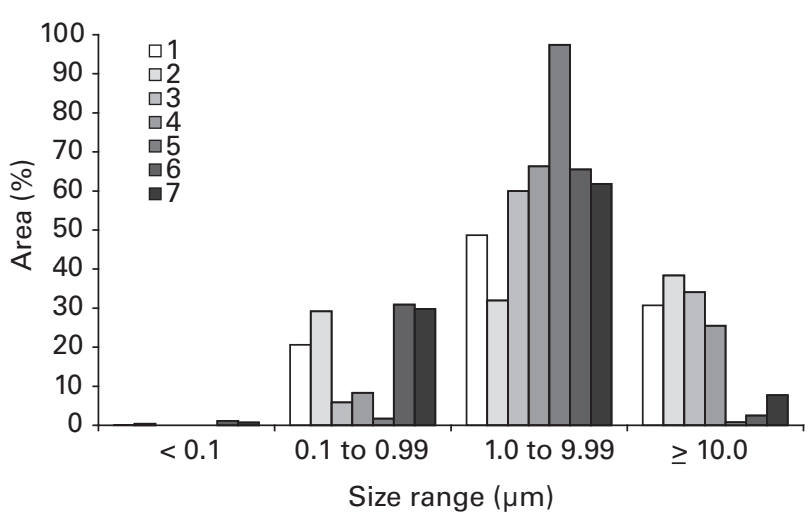

Fig. 4a

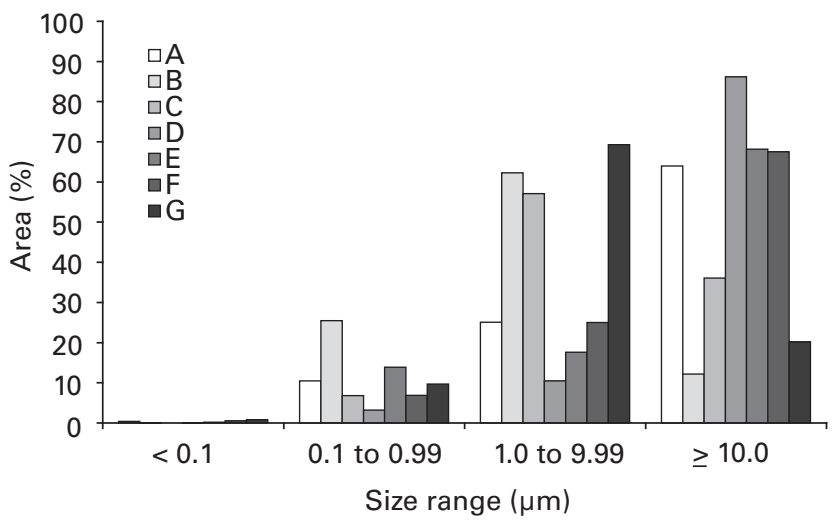

Fig. $4 b$

The percentage area distribution of ultra-high-molecular-weight polyethylene particles isolated from a) the seven samples of tissue compared with b) the seven samples of simulator lubricant.

was impossible. The silicon particles had a tendency to form distinctive, bright, chain-like agglomerations of rounded particles. Other elements identified by EDX analysis included aluminium, gold, molybdenum, sodium, calcium and potassium. These were not included in the size analysis.

Quantification of UHMWPE particles from both simulator serum and tissue samples. The mean number of particles isolated, counted and sized from the hip simulator lubricants was 442 per sample (201 to 769), compared with the tissues from which a mean of 398 particles (120 to 772) were counted per tissue sample. The percentage size distributions of particles isolated from the tissues and the simulator lubricants are shown in Figure 3. The size distribution of particles isolated from both the tissues and the simulator lubricants showed a negatively skewed normal distribution.
The mode of the percentage number of particles isolated from the tissues was in the size range $0.1 \mu \mathrm{m}$ to $0.99 \mu \mathrm{m}$. The mode of the percentage number of particles isolated from the simulator lubricants varied between samples, and was in the size ranges $<0.1 \mu \mathrm{m}$ or $0.1 \mu \mathrm{m}$ to $0.99 \mu \mathrm{m}$. A high degree of variability between the size distribution of particles from both the tissues and the hip lubricants was evident from the large error bars. The percentage area distributions of particles isolated from the tissues and simulator lubricants, as a function of size are shown in Figure 4. Particles in the size range $1.0 \mu \mathrm{m}$ to $9.99 \mu \mathrm{m}$ accounted for the largest proportion of the total wear volume in six of seven of the tissue samples, with tissue sample 2 being anomalous. The percentage area distribution of particles isolated from the simulator lubricants was more variable, with no obvious trend. The mean percentage number of 

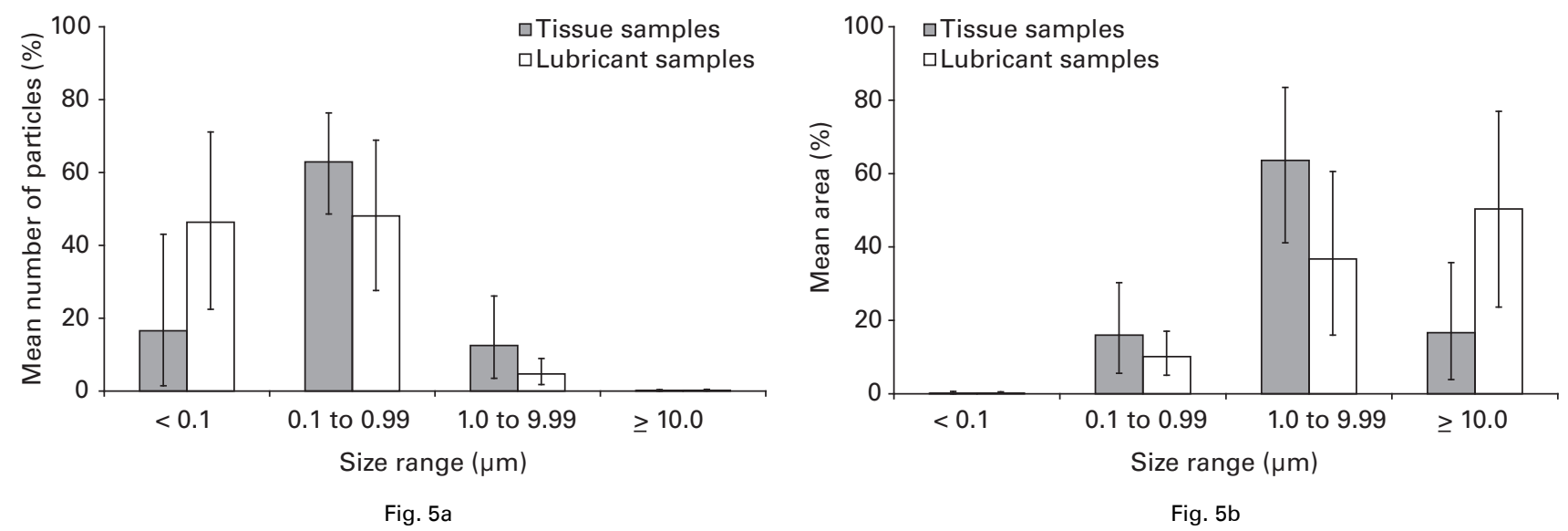

A comparison of a) the mean percentage number of particles and b) the mean percentage area of particles isolated from the tissue samples and the simulator lubricants. Error bars represent $95 \%$ confidence intervals.

Table II. Mass of ultra-high-molecular-weight polyethylene debris isolated from each tissue sample

\begin{tabular}{llllllll}
\hline Tissue sample & $\mathbf{1}$ & $\mathbf{2}$ & $\mathbf{3}$ & $\mathbf{4}$ & $\mathbf{5}$ & $\mathbf{6}$ & $\mathbf{7}$ \\
\hline Weight of debris isolated $(\mathrm{mg})$ & 0.584 & 1.915 & 1.062 & 0.366 & 0.407 & 0.485 & 0.187 \\
\hline
\end{tabular}

particles isolated from the tissue and the mean percentage area of particles isolated from the tissues compared with the hip simulator lubricants are shown in Figure 5. Overall, there were $50 \%$ fewer particles in the nanometre size range in the tissues than in the hip simulator lubricants. This was not statistically significant $(p=0.07)$. There were no statistically significant differences between the number of particles isolated in each size range isolated from the tissues and the hip simulator lubricants $(\mathrm{p}=0.07)$. Particles in the $\geq 10 \mu \mathrm{m}$ size range accounted for the majority of the volume of particles isolated from the hip simulator lubricants. This was significantly higher than the percentage areas of particles isolated from the tissues in the $\geq 10 \mu \mathrm{m}$ size range $(\mathrm{p}=0.03)$. It should be noted that a small number of large particles accounted for a large proportion of the total wear volume. This was especially true in the simulator lubricants (Fig. 5). Conversely, a high number of nanometre-sized particles represented only a small percentage of the total volume of wear debris.

Weight of particles isolated from the tissue samples. The mass of UHMWPE debris isolated onto the three filters from each individual tissue sample was recorded, and these weights are shown in Table II. It can be seen that tissue sample 2 had the largest total mass of debris isolated onto the filters $(1.915 \mathrm{mg})$. This was ten times higher than the mass isolated from tissue sample 7 , which had the least debris present. This was in agreement with the mode percentage area of particles isolated from tissue 2, falling in the largest size range of $\geq 10 \mu \mathrm{m}$ (Fig. 4).
Control samples. The mean amount of particulate contamination compared with the hip simulator lubricants was $11.11 \%(5.3 \%$ to $19.9 \%)$. The tissue samples are not comparable with the fetal bovine serum control, and therefore a mean contamination was not calculated for these samples. Particles contaminating the control samples were varied in size and shape. Most of the debris was in the $0.1 \mu \mathrm{m}$ to $0.99 \mu \mathrm{m}$ size range, but contaminating particles were found in all size ranges. Particles in the nanometre-sized range did not account for the majority of contamination.

\section{Discussion}

The use of the FEG-SEM and its superior resolution allowed nanometre-sized particles of polyethylene to be identified in peri-prosthetic tissue samples from failed Charnley hip prostheses. These were compared with particles isolated from samples of hip simulator lubricants. The mode number of particles isolated from tissue samples fell in the $0.1 \mu \mathrm{m}$ to $0.99 \mu \mathrm{m}$ size range, and the mode of the number of particles isolated from the hip simulator lubricants varied between the size ranges $<0.1 \mu \mathrm{m}$ and $0.1 \mu \mathrm{m}$ to $0.99 \mu \mathrm{m}$. There was less variability in the results of the percentage number of particles isolated from the tissues in the current study compared with the hip simulator lubricants. Although large numbers of nanometre-sized particles were isolated in both tissues and simulator lubricants, they accounted for only a small percentage of the total wear volume $(0 \%$ to $1.1 \%)$. Studies of nanometre-sized particles have to take into account the number and volume of parti- 
cles in this size range. Whereas $1 \mathrm{~mm}^{3}$ of polyethylene wear debris may include over up to $10^{12}$ particles $<100 \mathrm{~nm}$ in size, a total wear volume of $1 \mathrm{~mm}^{3}$ of wear debris generated may only contain $0.01 \mathrm{~mm}^{3}$ of particles $<100 \mathrm{~nm}$ in size. It is important to recognise clinically relevant dosing regimens in future studies when assessing the biocompatability of nanometre-sized polyethylene wear particles. The tissues had a higher percentage area of particles isolated in the $1.0 \mu \mathrm{m}$ to $9.99 \mu \mathrm{m}$ size range compared with the particles isolated from the simulator lubricants, which had a more variable distribution of percentage area. The mean data for the percentage area of particles isolated from the simulator lubricants showed that the mode percentage area of particles was in the size range $>10 \mu \mathrm{m}$. Although not significantly different, the percentage number of nanometre particles isolated from the tissue samples was markedly lower than for the lubricant samples. One explanation for this is that there were simply fewer nanometre particles produced in vivo. Secondly, variations in the sizes of particles produced could result from patient variability, including activity levels, kinematics, implant head roughness and alignment. Thirdly, particles of UHMWPE have been identified at sites that were distal to the point of implantation. Gray et $\mathrm{al}^{23}$ reported histological changes in the lymph nodes of patients with hip prostheses, including dilated nodal sinuses containing macrophages, granulomatous material and foreign particles within the phagocytes. These studies indicate that when particles are liberated into the peri-prosthetic tissue they have the potential to disseminate away from the site of implantation via the natural lymphatic system or tissue damage. Particles that are disseminated furthest away are likely to be those in the smallest size range, the nanometre-sized particles, and this may be reflected in the results of this study. Larger particles would be more likely to be retained in the tissues near the implant. In the hip simulator each station is enclosed by a flexible silicone bag. There is no natural filtration of large and small particles, and so any nanometre-sized particles would be retained. Additionally, polyethylene in patients is subject to ageing and oxidation. These can cause differences in particle size, as can the small differences in molecular weights of the polyethylene components in the patients compared with the polyethylene acetabular components used in the simulator studies.

The EDX analysis used in this study showed that many types of particle were identified, including metallic, ceramic, salts and biological contaminants. Silicon can come from a number of sources, but is likely to be an environmental contaminant. Tissue samples collected at the time of revision may also contain environmental silicon debris. The percentage contamination calculation in the current study was greater than the $2 \%$ estimated previously by Tipper et al. ${ }^{17}$ The advantage of using high-resolution FEG-SEM was that contamination could be excluded in the final analysis, as particle morphology coupled with EDX analysis could be used to determine which particles were polyethylene and which were not. Automated methods of sizing are likely to underestimate the numbers of nanometre particles present, as individual particles held within agglomerates cannot be sized. Mochida et $\mathrm{a}^{24}$ and Maloney et $\mathrm{al}^{25}$ digested tissues using concentrated nitric acid and papain, respectively. They independently analysed the debris isolated while suspended in solution using a Coulter Multisizer. Mochida et $\mathrm{al}^{24}$ gave a mean particle diameter of $0.40 \mu \mathrm{m}$ and Maloney et $\mathrm{al}^{25}$ reported a mean diameter of particle of $0.63 \mu \mathrm{m}$. This is over ten times larger than the smallest particle identified in our study. The results of our study were comparable with those of Tipper et $a{ }^{2}{ }^{2}$ in which particles were isolated from 18 acetabular and femoral tissue samples taken from failed Charnley hip prostheses. Tissues were retrieved from implants which had a mean time in vivo of 12.88 years, compared with the current study where the mean implant life was 14.1 years. Both studies have shown that the mode number of particles isolated from tissue samples falls in the $0.1 \mu \mathrm{m}$ to $0.99 \mu \mathrm{m}$ size range. However, this study also had the benefit of using FEG-SEM, and was able to characterise the lower end of the size distribution of UHMWPE particles, i.e. those in the size range $<0.1 \mu \mathrm{m}$. Scott et $\mathrm{al}^{10,18}$ used acid to digest samples of hip simulator lubricants and filtered the digests through $0.2 \mu \mathrm{m}$ and $0.05 \mu \mathrm{m}$ filters. The maximum resolution used was a magnification power of $20 \mathrm{~K}$, and most of the submicrometre debris identified had settled on the $0.2 \mu \mathrm{m}$ filter. The submicrometre particles were rounded and granular in shape, similar to those isolated and identified in this study. A higher percentage number of these granular, submicrometre particles were produced by the 100000 Grays cross-linked UHMWPE tested by Scott et al, ${ }^{18}$ compared with conventional and 50000 Grays crosslinked UHMWPE. Particles were identified that were 80 $\mathrm{nm}$ or less in diameter. Cross-linking is now used to reduce the wear of UHMWPE. However, studies such as those by Galvin et $\mathrm{a}^{16}$ and Scott et $\mathrm{a}^{18}$ showed that cross-linking may cause the size distribution of the wear debris produced to shift to a smaller size range. Tipper et al ${ }^{17}$ studied the wear debris produced by moderately cross-linked UHMWPE produced from GUR 1020 resin and found particles down to 10 $\mathrm{nm}$ in hip and knee simulator lubricants. Tipper et $\mathrm{al}^{17}$ used FEG-SEM with a maximum magnification of $65 \mathrm{~K}$. All three studies ${ }^{16-18}$ found a high degree of variability in their results of particle quantification from hip simulator lubricants when using manual SEM methods of analysis, as did our study. Manual sizing can lead to variations in results, but it does have the advantage of direct visualisation of the particles, including those in the nanometre-sized range.

It is important that in vitro simulations produce wear debris that is clinically relevant, if it is to be used as a model to predict long-term failure due to osteolysis. This is the first study to support the data produced by hip simulators and confirm that nanometre-sized particles are generated in vivo, albeit that the hip simulator ran for 5 million cycles only, whereas the number of cycles a hip undergoes in vivo 
is unknown. Little is known about how the body deals with nanometre-sized UHMWPE wear debris, and further work is required to establish the biological activity of particles in the size range $0.01 \mu \mathrm{m}$ to $0.1 \mu \mathrm{m}$. Additionally, it would be interesting to assess the potential of nanometre particles to disseminate from the site of the implant, as the biological consequences of long-term storage of nanometre-sized polyethylene particles within the body are unknown at present.

Nanometre-sized particles were identified both in tissue samples retrieved from failed Charnley hip prostheses and in the lubricating serum used in hip simulators. The significance of these findings in terms of the biological response to these particles in the body remains to be determined.

L. Richards was supported by a PhD studentship grant from Engineering and Physical Sciences Research Council (EPSRC) in collaboration with DePuy International. Dr J. L. Tipper is supported through an EPSRC Advanced Fellowship. Hip simulators have been supported by Arthritis Research Campaign and EPSRC.

The author or one or more of the authors have received or will receive benefits for personal or professional use from a commercial party related directly or indirectly to the subject of this article.

\section{References}

1. Campbell P, Doorn P, DOrey F, Amstutz HC. Wear and morphology of ultra high molecular weight polyethylene wear particles from total hip replacements. Proc Inst Mech Eng [H] 1996;210:167-74.

2. Tipper JL, Ingham $\mathbf{E}$, Hailey JL, et al. Quantitative analysis of polyethylene wear debris, wear rate and head damage in retrieved Charnley hip prostheses. $J$ Mater Sci Mater Med 2000;11:117-24.

3. Doorn PF, Campbell PA, Amstutz HC. Metal versus polyethylene wear particles in total hip replacement: a review. Clin Orthop 1996;329(Suppl):206-16.

4. Kobayashi A, Freeman MAR, Bonfield W, et al. Number of polyethylene particles and osteolysis in total joint replacements: a quantitative study using a tissue digestion method. J Bone Joint Surg [Br] 1997;79-B:844-8.

5. Schmalzried TP, Jasty M, Rosenberg A, Harris WH. Histological identification of polyethylene wear debris using Oil Red 0 stain. J Appl Biomater 1993:4:119-25

6. Guttmann D, Schmalzried TP, Jasty M, Harris WH. Light microscopic identification of submicron polyethylene wear debris. J Appl Biomater 1993;4:303-7.

7. Campbell P, Ma S, Schmalzried T, Amstutz HC. Tissue digestion for wear particle isolation. J Biomed Mater Res 1994;28:523-6.
8. Baxter RM, Tipper J, Steinbeck MJ, et al. Identification of optimal tissue digestion methods for polyethylene wear debris analysis. [abstract]. Soc Biomater 2006:239.

9. Slouf M, Eklova S, Kumstatova J, et al. Isolation, characterization and quantification of polyethylene wear debris from periprosthetic tissues around total joint replacements. Wear 2007;262:1171-81.

10. Scott M, Widding K, Jani S. Do current wear particle isolation procedures underestimate the number of particles generated by prosthetic bearing components? Wear 2001;251:1213-17.

11. Elfick APD, Green SM, Krikler S, Unsworth A. The nature and dissemination of UHMWPE wear debris retrieved from periprosthetic tissue of THR. J Biomed Mater Res A 2003;65:95-108.

12. Elfick APD, Smith SL, Green SM, Unsworth A. The quantitative assessment of UHMWPE wear debris produced in hip simulator testing: the influence of head material and roughness, motion and loading. Wear 2001;249:517-27.

13. Shanbhag AS, Jacobs JJ, Glant $\mathbf{T}$, et al. Composition and morphology of wear debris in failed uncemented total hip replacement. J Bone Joint Surg [Br] 1994;76-B:60-7.

14. Affatato S, Fernandes B, Tucci A, Esposito L, Toni A. Isolation and morphological characterisation of UHMWPE wear debris generated in vitro. Biomaterials 2001;22:232531.

15. Visentin M, Stea S, Squarzoni S, et al. A new method for isolation of polyethylene wear debris from tissue and synovial fluid. Biomaterials 2004;25:5531-7.

16. Galvin AL, Tipper JL, Ingham E, Fisher J. Nanometre size wear debris generated from crosslinked and non-crosslinked ultra high molecular weight polyethylene in artificial joints. Wear 2005;259:977-83.

17. Tipper JL, Galvin AL, Williams S, et al. Isolation and characterisation of UHMWPE wear particles down to ten nanometres in size from in vitro hip and knee joint simulators. J Biomed Mater Res 2006;78:473-80.

18. Scott M, Morrison M, Mishra SR, Jani S. Particle analysis for the determination of UHMWPE wear. J Biomed Mater Res B Appl Biomater 2005;73:325-37.

19. Green TR, Fisher J, Stone MH, Wroblewski BM, Ingham E. Polyethylene particles of a 'critical size' are necessary for the induction of cytokines by macrophages in vitro. Biomaterials 1998; 19:2297-302.

20. Ingram J, Matthews JB, Tipper JL, et al. Comparison of the biological activity of grade GUR 1120 and GUR 415HP UHMWPE wear debris. Biomed Mater Eng 2002;12:177-88.

21. Ingram JH, Stone $\mathbf{M}$, Fisher J, Ingham $\mathbf{E}$. The influence of molecular weight, crosslinking and counterface roughness on TNF-alpha production by macrophages in response to ultra high molecular weight polyethylene particles. Biomaterials 2004;25:3511-22.

22. Sokal RR, Rohlf FJ. Biometry: the principles of practice of statistics in biological research. Second ed. New York: W. H. Freeman and Company 1981:246-7.

23. Gray MH, Talbert ML, Talbert WM, Bansal M, Hsu A. Changes seen in lymph nodes draining the sites of large joint prostheses. Am J Surg Pathol 1989;13:1050-6.

24. Mochida Y, Boehler M, Salzer M, Bauer TW. Debris from failed ceramic-on-ceramic and ceramic-on-polyethylene hip prostheses. Clin Orthop 2001;389:113-25.

25. Maloney WJ, Smith RL, Schmalzried TP, et al. Isolation and characterisation of wear particles generated in patients who have had failure of a hip arthroplasty without cement. J Bone Joint Surg [Am] 1995;77-A:1301-10. 